\title{
Conservação pós-colheita de diferentes cultivares de mandioca submetidas ao processamento mínimo e congelamento
}

\section{Post-harvest conservation of different cassava cultivars subjected to minimal processing and freezing}

\author{
Maria Madalena RINALDI ${ }^{\text {; }}$ Eduardo Alano VIEIRA²; Josefino de Freitas FIALHO; \\ 1 Autor para correspondência. Pesquisadora Classe A, Doutora em Ciência e Tecnologia Pós-colheita, Embrapa \\ Cerrados (CPAC) Rodovia BR-020, km 18 Caixa Postal: 08223 CEP: 73310-970 - Planaltina - DF. \\ madalena.rinaldi@embrapa.br \\ 2 Pesquisador Classe A, Doutor em Recursos Genéticos e Melhoramento Vegetal, Embrapa Cerrados (CPAC) \\ Planaltina, DF. eduardo.alano@embrapa.br \\ ${ }^{3}$ Pesquisador Classe B, Mestre em Fitotecnia, Embrapa Cerrados (CPAC) Planaltina, DF. josefino.fialho@embrapa.br
}

Recebido em: 07-10-2014; Aceito em: 07-05-2015

\begin{abstract}
Resumo
A demanda dos consumidores por raízes de mandioca de mesa in natura está decrescendo, em função da elevada perecibilidade das mesmas e do aspecto visual pouco atrativo. Como consequência, vem crescendo a comercialização do produto minimamente processado ou processado na forma de pré-cozido, congelado e massa, tanto para o mercado interno como para exportação. O objetivo do estudo foi determinar a conservação pós-colheita de raízes de cultivares de mandioca de mesa com coloração da polpa rosada (BRS 400), amarela (BRS 399) e creme (IAC 576-70), recomendadas para a região do Distrito Federal e Entorno, minimamente processadas e acondicionadas em embalagem de polietileno com e sem vácuo, submetidas à refrigeração e congelamento a $-18^{\circ} \mathrm{C}$. Durante o armazenamento, foram realizadas análises físico-químicas e microbiológicas. O tempo de armazenamento e os tratamentos influenciaram na qualidade das raízes de mandioca minimamente processadas. Considerando as análises microbiológicas, as raízes de mandioca das diferentes cultivares estudadas, minimamente processadas, mantidas congeladas, podem ser comercializadas durante 28 dias em boas condições de consumo. Sob refrigeração com e sem vácuo, a vida útil das raízes das diferentes variedades é de, no máximo, sete dias. Raízes de mandioca das cultivares BRS 400, BRS 399 e IAC 576-70 não apresentam variação significativa na coloração quando mantidas sob refrigeração, com e sem vácuo, e congeladas durante 28 dias de armazenamento. As três variedades de mandioca apresentam maior vida útil quando submetidas sob congelamento, sendo uma alternativa para o aumento da vida útil de raízes de mandioca minimamente processadas.
\end{abstract}

Palavras-chave adicionais: aipim; armazenamento; mandioca de mesa; Manihot esculenta Crantz; vida útil.

\begin{abstract}
Consumer demand for in natura cassava roots has been decreasing because of its high perishability and unattractive visual appearance. As a result, minimally processed or pre-cooked, frozen and pasta cassava consumption is increasing both domestically and for export. The aim of the study was to determine post-harvest conservation of roots of cassava cultivars with pulp color rosy (BRS 400), yellow (BRS 399) and cream (IAC 576-70), recommended for the region of the Brazil Federal District and surrounding areas, subject to minimal processing and packed in polyethylene bags with and without vacuum submitted to cooling and freezing at $-18^{\circ} \mathrm{C}$. During storage physicochemical and microbiological analyses were performed. The storage and treatment influenced the quality of minimally processed cassava roots. Whereas microbiological analyzes of different cultivars of minimally processed and frozen cassava roots can be sold during a period of 28 days in good condition. Under cooling with and without vacuum, the life span of the minimally processed roots of the different varieties is at maximum seven days. Cassava roots of BRS 400, BRS 399 and IAC 576-70 don't present significant variation in color when kept under refrigeration with and without vacuum and frozen for 28 days of storage. The three varieties of cassava have longer life when subjected under freezing, it might be an alternative to increasing the shelf-life of minimally processed cassava roots.
\end{abstract}

Additional keywords: Manihot esculenta Crantz; minimal processing; shelf-life; storage; temperature. 


\section{Introdução}

A mandioca (Manihot esculenta Crantz) tem ampla adaptação a diferentes condições de solo e clima, sendo cultivada em todo o Brasil (Albuquerque et al., 2014). É a maior fonte de carboidratos para mais de 800 milhões de pessoas em vários países tropicais (Moura et al., 2013). Desempenha importante papel na dieta alimentar dos brasileiros, representando para muitas famílias do Norte e Nordeste a principal fonte energética (Suppakul et al., 2013; Mezzalira et al., 2013). Em 2012, o Brasil foi o segundo maior produtor mundial de mandioca, com 25.744.829 toneladas de raízes (Farias Neto et al., 2013).

A cultura tem destaque especialmente em países em desenvolvimento, principalmente em razão de sua rusticidade e da capacidade de produzir elevadas quantidades de amido em condições em que outras culturas sequer sobreviveriam (Vieira et al., 2011). No Brasil, a mandioca situa-se entre as principais culturas do país, a maior parte cultivada por pequenos e médios produtores (Mezette et al., 2013). No ano de 2014, o Brasil produziu, aproximadamente, 24 milhões de toneladas de raízes de mandioca em uma área colhida de 1.592.091 hectares (Agrianual, 2015). A região Norte representa $33,5 \%$ da produção nacional, seguida da região Nordeste com $25,6 \%$, destacando-se o Estado do Pará como sendo o maior produtor brasileiro (Agrianual, 2015). De acordo com Halsey et al. (2008), a região dos Cerrados do Brasil é um dos principais centros de dispersão da mandioca. El-Sharkawy (2012) afirma que esta é uma das culturas mais indicadas para a região em razão de sua grande rusticidade. Ela é cultivada visando principalmente ao aproveitamento de suas raízes tuberosas, ricas em amido.

Atualmente, a cultivar de mandioca de mesa mais plantada da região do Distrito Federal e Entorno é a IAC 576-70, que é popularmente conhecida na região como Japonesinha. Recentemente, a equipe de melhoramento genético de mandioca da Embrapa Cerrados recomendou para a região as cultivares de mandioca de mesa BRS 399, com polpa mais amarela que a IAC 576-70, e a cultivar BRS 400, com polpa rosada. A coloração da polpa das raízes amarela está relacionada à presença de betacaroteno e de licopeno nas raízes de coloração rosada.

$\mathrm{Na}$ comercialização das raízes, além da pouca aceitabilidade pelo consumidor devido à dificuldade de descasque e pouca praticidade, a manutenção das raízes frescas por vários dias após a colheita é um dos maiores problemas da comercialização in natura e de raízes processadas (Ramos et al., 2013). Devido a isso, nos grandes centros urbanos, além das raízes de mandioca de mesa in natura, as mesmas também são comercializadas de forma minimamente processada ou processada, pré-cozidas, congeladas e massas. Esse mercado está em expansão, tanto para o abastecimento interno como para exportação; todavia, devido à deterioração pós-colheita, exige abastecimento contínuo (Aguiar et al., 2011).

Os alimentos minimamente processados surgiram para dar resposta a uma nova tendência de consumo e têm tido uma aceitação cada vez maior nos mercados mundiais (Santos \& Oliveira, 2012). Esses alimentos são, habitualmente, comercializados já embalados para maior comodidade. Em seu processamento, apenas ocorre diminuição moderada da flora microbiana presente, não havendo a esterilização do produto, exigindo-se um processo de refrigeração rigoroso, para evitar o crescimento de microrganismos patogênicos e deterioradores. É importante ressaltar que um produto minimamente processado deve apresentar vida útil de forma a garantir sua comercialização, sendo que um dos maiores problemas dos mesmos é sua rápida deterioração (Arruda et al., 2011).

Dessa forma, o congelamento das raízes após o processamento mínimo poderá auxiliar na manutenção do produto em condições adequadas de consumo. De acordo com Oliveira (2010), dentre os vários métodos que podem ser empregados para a conservação das raízes de mandioca descascadas, o congelamento mostra-se eficiente por controlar ambos os tipos de deterioração: fisiológica e microbiológica. O congelamento consiste num dos métodos mais difundidos e utilizados na preservação de diversos alimentos, devido à conservação de suas qualidades (Carvalho et al., 2011).

Buscando auxiliar na conservação e na comercialização de raízes de mandioca minimamente processadas, o objetivo do estudo foi determinar a conservação pós-colheita de raízes, de três cultivares de mandioca, recomendadas para a região do Distrito Federal e Entorno, submetidas ao processamento mínimo e acondicionadas em embalagem de polietileno, com e sem vácuo, submetidas à refrigeração e ao congelamento.

\section{Material e métodos}

No mesmo experimento, utilizaram-se raízes de mandioca da cultivar de mesa com coloração creme da polpa das raízes da IAC 576-70, conhecida popularmente na região do Cerrado como Japonesinha. Também foram utilizadas no estudo raízes das cultivares de mandioca de mesa com polpa amarela (BRS 399) e com polpa rosada (BRS 400)

Aos doze meses após o plantio, foi efetuada a colheita das raízes, momento em que elas foram transportadas para o laboratório, lavadas em água corrente e resfriadas em câmara fria $(10 \pm 1 \stackrel{\circ}{\circ} \mathrm{e}$ $95 \%$ de umidade relativa). O processamento mínimo consistiu no descasque manual das raízes e descarte das pontas; lavagem em água corrente; corte da parte mediana das raízes em cilindros $(10 \mathrm{~cm}$ de comprimento) e corte desses cilindros longitudinalmente em quatro partes; imersão (10 minutos) em solução sanificante de hipoclorito de sódio com $150 \mathrm{mg} \mathrm{L}^{-1}$ de cloro ativo; enxague (5 minutos) em 
solução de $5 \mathrm{mg} \mathrm{L}^{-1}$ do mesmo sanificante, e drenagem das raízes por cinco minutos em escorredor de aço inoxidável, semelhante aos utilizados em restaurantes semi-industriais.

A temperatura da água de lavagem, na sanitização e nos enxágues, foi mantida a $5 \pm 2{ }^{\circ} \mathrm{C}$, sendo controlada com a adição de gelo à mesma. $A$ área de processamento foi previamente higienizada, bem como todos os utensílios mantidos em seu interior. A temperatura do ambiente foi mantida a $15 \pm 3 \stackrel{\circ}{\circ}$ e utilizaram-se equipamentos de proteção individual (EPIs).

$\mathrm{O}$ produto minimamente processado $(500 \mathrm{~g})$ foi acondicionado em embalagem de polietileno de baixa densidade (PEBD), com $100 \mu \mathrm{m}$ de espessura, com e sem vácuo, e submetido à refrigeração em câmara fria na temperatura de $3^{\circ} \mathrm{C}$ e $95 \%$ de umidade relativa. Somente o produto sem vácuo foi submetido ao congelamento e ao armazenamento em temperatura de $-18{ }^{\circ} \mathrm{C}$. O período de armazenamento foi de 28 dias para todos os tratamentos.

Após o processamento mínimo, o produto foi caracterizado quanto à umidade e aos sólidos totais por meio do método gravimétrico descrito por Carvalho et al. (1990). Logo após o processamento mínimo e aos sete, 14; 21 e 28 dias de armazenamento, o produto foi submetido à análise de $\mathrm{pH}$, acidez titulável, sólidos solúveis e ratio, de acordo com Carvalho et al. (1990); tempo para a cocção conforme descrito por Butarelo et al. (2004), e cor ( $L^{\#}$, $\left.a^{*}, b^{*}\right)$ determinada em espectrofotômetro MiniScan ${ }^{\circledR}$ EZ, marca HunterLab, sendo realizadas cinco leituras por raiz de mandioca. $O$ valor de $L^{\#}$ define a luminosidade $\left(L^{\#}=0\right.$ preto e $L^{\#}=100$ branco) e $a^{*} e b^{*}$ são responsáveis pela cromaticidade $\left(+a^{*}\right.$ vermelho e - $a^{*}$ verde), $b^{*}\left(+b^{*}\right.$ amarelo e $-b^{*}$ azul). Por meio do módulo $L^{\#}$, $a^{*}$ e $b^{*}$, foi possível calcular o croma (saturação ou intensidade da cor; 0 - cor impura e 60 - cor pura) e o ângulo hue (ângulo da cor; $0^{\circ}$ vermelho; $90^{\circ}$ amarelo; $180^{\circ}$ verde; $270^{\circ}$ azul e $360^{\circ}$ negro) por meio das fórmulas: croma $\left[\left(a^{2}+b^{2}\right)^{1 / 2}\right]$ e ângulo hue [arco tangente (b/a)], conforme recomendado por Hunterlab (2008). Também foram realizadas as análises microbiológicas de acordo com Silva et al. (2007). Analisou-se a contagem total de aeróbios mesófilos, psicrotróficos, bolores e leveduras, coliformes totais e termotolerantes.

O delineamento experimental utilizado foi o inteiramente casualizado, com três repetições para cada tratamento, sendo que cada repetição consistiu em uma embalagem contendo $500 \mathrm{~g}$ de raízes de mandioca minimamente processadas. Os dados foram submetidos à análise de variância fatorial simples para cada cultivar, individualmente, utilizando o teste $F$, e as médias foram agrupadas por meio do teste aglomerativo de Scott e Knott, a 5\% de probabilidade de erro. Todas as análises estatísticas foram realizadas com o auxílio do programa estatístico Genes (Cruz, 2001).

\section{Resultados e discussão}

\section{Caracterização geral}

Para a cultivar de mandioca rosada (BRS 400 ), a umidade das raízes foi de $66,84 \%$, e os sólidos totais, de $33,15 \%$, e a cultivar com polpa amarela (BRS 399) apresentou $72,15 \%$ de umidade e $27,85 \%$ de sólidos totais, enquanto para a cultivar com coloração da polpa das raízes creme (IAC 576-70) a umidade das raízes foi de $64,48 \%$ e os sólidos totais de $35,51 \%$. Resultados apresentados pela Taco (2011) em raízes de mandioca crua revelaram valores muito próximos aos obtidos neste trabalho para a umidade $(61,80 \%)$. Por sua vez, Feniman (2004) analisou a cultivar IAC 576-70 na mesma época de colheita das raízes utilizadas neste trabalho, encontrando $66,86 \%$ de umidade nas raízes.

Oliveira et al. (2003) observaram valores de umidade entre $63,60 \%$ e $65,54 \%$ para mandioca minimamente processada durante 28 dias de armazenamento, valores estes próximos aos encontrados neste trabalho. A cultivar Baianinha minimamente processada apresentou valor médio de 57,01\% durante o armazenamento (Bezerra et al., 2002). Para Carvalho et al. (2011), o valor médio de umidade verificado para as raízes de mandioca congeladas e armazenadas durante 150 dias foi de $60,65 \%$. Várias cultivares de mandioca descascada, cortada, armazenada em embalagens plásticas e submetidas a congelamento a $-8^{\circ} \mathrm{C}$ por dois meses apresentaram umidade média em torno de 65,00\% (Ceni et al., 2009). Esses resultados estão próximos aos valores de umidade $(64,48 \%$ a $72,15 \%)$ obtidos no presente estudo para as diferentes cultivares de mandioca. Os maiores valores de umidade obtidos neste trabalho podem estar relacionados a diferentes variedades avaliadas, e também por estarem sendo apresentados valores de umidade somente após o processamento do produto, ao invés de durante todo o armazenamento, como ocorreu em todos os trabalhos citados acima, uma vez que durante 0 armazenamento do produto pode haver redução nos valores de umidade das raízes de mandioca devido à perda de massa fresca e a reações ocorridas no próprio produto durante este período.

Mezette et al. (2009) encontraram teor de matéria seca na mandioca cultivar IAC 576-70 de $43,58 \%$, sendo superior aos valores encontrados neste trabalho. Feniman (2004) obteve valor médio inferior $(33,10 \%)$ para a mesma cultivar IAC 576-70 utilizada neste estudo. Pereira \& Beléia (2004) encontraram valor de 40,90\% para a cultivar IAPAR 19 (Pioneira) e 42,30\% para a cultivar Catarina Amarela, sendo superior aos valores observados neste trabalho para os diferentes clones. De acordo com Fukuda et al. (2006), os teores de matéria seca nas raízes são altamente relacionados com os teores de amido ou fécula, dependendo da variedade, do local de cultivo, da idade e da época de colheita. 


\section{Cultivar de mandioca com raízes de coloração rosada BRS 400}

Para a cultivar de mandioca com coloração da polpa das raízes rosada (BRS 400), os valores de sólidos solúveis variaram entre 3,40 e 6,40 Brix com valor médio de 4,39 Brix (Tabela 1). Não foi verificado efeito significativo dos tratamentos, e do período de armazenamento sobre essa variável.
Silva et al. (2003) observaram variação de 4,0 Brix a 6,0 ${ }^{\circ}$ Brix durante o armazenamento de raízes de mandioca cacau minimamente processadas. A variação nos sólidos solúveis durante a armazenagem pode ser devida às características intrínsecas da amostra ou por reações metabólicas ocorridas durante o armazenamento das amostras, utilizando - açúcar como substrato, e também à atividade microbiana no produto mantido sob refrigeração.

Tabela 1 - Resumo da análise de variância com indicação dos graus de liberdade (GL), quadrados médios (QM) e coeficientes de variação (CV) dos caracteres $\mathrm{pH}$, sólidos solúveis em ${ }^{\circ}$ Brix (SS), acidez titulável em $\mathrm{g}$ de ácido cítrico em 100 gramas de matéria fresca $(\mathrm{AT})$, ratio, luminosidade $\left(\mathrm{L}^{\#}\right)$, croma, ângulo hue $\left(^{\circ}\right)$ e tempo para a cocção (TC), avaliados em raízes da cultivar de mandioca BRS 400 (polpa rosada) minimamente processadas, submetidas ao tratamentos refrigerado sem vácuo, refrigerado com vácuo e congelamento sem vácuo, e armazenamento a $-18^{\circ} \mathrm{C}$; em função dos dias de armazenamento. Summary of analysis of variance indicating the degrees of freedom (DF), mean squares (QM) and coefficients of variation (CV) of characters $\mathrm{pH}$, Brix soluble solids (SS), titratable acidity in g citric acid in 100 grams of fresh matter $(A T)$, ratio, luminosity ( $\left.\mathrm{L}^{\#}\right)$, chroma, hue angle $\left(^{\circ}\right)$ and time for cooking (TC), measured in pink BRS 400 cassava roots that were minimally processed subjected to cold treatments without vacuum, with cooled vacuum and non-vacuum freezing and at $-18^{\circ} \mathrm{C}$ storage; a function of days of storage.

\begin{tabular}{lccrrrrrrr}
\hline \multirow{2}{*}{ Fontes de Variação } & \multirow{2}{*}{$\mathrm{GL}$} & \multicolumn{10}{c}{ QM } \\
\cline { 3 - 10 } & & $\mathrm{pH}$ & $\mathrm{SS}$ & $\mathrm{AT}$ & Ratio & \multicolumn{1}{c}{$\mathrm{L}^{\#}$} & Croma & Ângulo hue & $\mathrm{TC}$ \\
\hline Tratamentos (T) & 2 & $0,12^{*}$ & 0,66 & $0,003^{*}$ & $2396^{*}$ & 10,85 & $20,48^{*}$ & 5,82 & 4,01 \\
Armazenamento (A) & 4 & $0,16^{*}$ & 1,47 & $0,003^{*}$ & $5523^{*}$ & 4,76 & $6,85^{*}$ & $57,39^{*}$ & $19,11^{*}$ \\
T x A & 8 & $0,05^{*}$ & 0,14 & $0,0001^{*}$ & $2030^{*}$ & 3,75 & $9,77^{*}$ & 31,22 & $4,63^{*}$ \\
Resíduo & 30 & 0,0003 & 0,74 & 0,0003 & $428^{*}$ & 3,67 & 2,00 & 16,56 & 1,29 \\
\hline Média & - & 6,57 & 4,39 & 3,69 & 128,30 & 81,60 & 17,36 & 52,59 & 29,27 \\
CV (\%) & - & 8,34 & 19,58 & 14,85 & 16,12 & 2,35 & 8,14 & 7,74 & 3,88 \\
\hline
\end{tabular}

${ }^{\text {}}$ Significativo a $5 \%$ de probabilidade de erro, pelo teste $\mathrm{F}$.

Os valores de luminosidade $\left(L^{\#}\right)$ variaram entre 73,64 e 85,34, com valor médio de 81,60 (Tabela 1), não tendo sido detectadas diferenças significativas durante o período de armazenamento e os tratamentos, indicando que não houve variação significativa na cor da mandioca durante os 28 dias de armazenamento, ou seja, as raízes de mandioca não apresentaram escurecimento durante o armazenamento.

Os valores de $\mathrm{pH}$ (Tabela 2) apresentaram oscilação em todos os tratamentos durante os 28 dias de armazenamento. Os maiores valores foram observados no produto acondicionado a vácuo, mantido sob refrigeração a partir de 21 dias, correspondendo aos menores valores de acidez titulável durante o armazenamento (Tabela 2). Os menores valores foram obtidos no produto congelado, também correspondendo à menor redução da acidez titulável. De acordo com Chitarra \& Chitarra (2005), o pH tende a aumentar com a redução da acidez em produtos armazenados em função do consumo dos ácidos orgânicos como substratos no processo respiratório, ocasionando assim aumento do $\mathrm{pH}$. Toletes de mandioca acondicionados em sacos de polietileno + EVOH, armazenados sob temperatura de $4 \stackrel{\circ}{\circ}$ por 28 dias, apresentaram valor médio de $\mathrm{pH}$ de 6,89 (Oliveira et al., 2003), situando-se na faixa de valores $(6,37$ a 7,03$)$ observados no presente estudo.

De maneira geral, a acidez titulável apresentou redução durante 0 armazenamento em todos os tratamentos, com algumas oscilações nos valores, provavelmente devido às características intrínsecas da própria amostra (raiz). O congelamento foi mais efetivo na manutenção da acidez das raízes durante o armazenamento, provavelmente devido à menor atividade metabólica e microbiana no produto submetido a este tratamento. Raízes de mandioca congelada por até 60 dias de estocagem não apresentaram diferença significativa nos valores de acidez titulável; entretanto, a partir dos 90 dias de armazenamento, apresentaram acréscimo significativo em relação aos períodos anteriores (Carvalho et al., 2011).

Os valores de ratio variaram entre 92,02 e 197,40 , refletindo o comportamento dos componentes isoladamente (Tabela 2). As raízes acondicionadas sob vácuo, mantidas sob refrigeração, apresentaram os maiores valores de ratio, correspondendo aos menores valores de acidez titulável, sendo que não ocorreu variação significativa nos valores de sólidos solúveis no armazenamento desta variedade de mandioca. Os menores valores foram obtidos no 
produto mantido apenas sob refrigeração, onde ocorreram os menores valores de sólidos solúveis, provavelmente devido ao consumo de açúcares no processo respiratório das raízes. Segundo Cavalini (2004), os valores de ratio tendem a aumentar durante a maturação do vegetal, devido ao acréscimo nos teores de açúcares e à diminuição dos ácidos. Esse comportamento não ocorreu neste experimento, sendo que a variação nos valores de ratio correspondem ao ocorrido nos valores de sólidos solúveis e acidez titulável, ou seja, quando houve aumento dos sólidos solúveis e redução da acidez titulável ocorreu aumento nos valores de ratio, e vice-versa.

Tabela 2 - Valores médios(@) de pH, acidez titulável, ratio, croma, ângulo hue e tempo para a cocção em raízes da cultivar de mandioca BRS 400 (polpa rosada) minimamente processadas, submetidas a diferentes tratamentos. Average values of $\mathrm{pH}$, titratable acidity, ratio, chroma, hue angle and time for cooking in cassava roots submitted BRS 400 (rosy pulp) minimally processed the different treatments.

\begin{tabular}{|c|c|c|c|c|c|}
\hline \multirow{3}{*}{ Tratamentos } & \multicolumn{5}{|c|}{ Dias de armazenamento } \\
\hline & 0 & 7 & 14 & 21 & 28 \\
\hline & \multicolumn{5}{|c|}{$\mathrm{pH}$} \\
\hline Refrigerado sem Vácuo & $6,45 \mathrm{Ea}$ & $6,55 \mathrm{Da}$ & $6,62 \mathrm{Ca}$ & $6,67 \mathrm{Bb}$ & $6,69 \mathrm{Ab}$ \\
\hline Refrigerado com Vácuo & $6,45 \mathrm{Ca}$ & $6,42 \mathrm{Dc}$ & $6,46 \mathrm{Cb}$ & $6,84 \mathrm{Ba}$ & $7,03 \mathrm{Aa}$ \\
\hline \multirow[t]{2}{*}{ Congelado sem Vácuo } & $6,46 \mathrm{Da}$ & $6,48 \mathrm{Cb}$ & $6,37 \mathrm{Ec}$ & $6,50 \mathrm{Bc}$ & $6,54 \mathrm{Ac}$ \\
\hline & \multicolumn{5}{|c|}{ Acidez titulável (g de ácido cítrico/100 g de matéria fresca) } \\
\hline Refrigerado sem Vácuo & $0,04 \mathrm{Aa}$ & $0,03 \mathrm{Bb}$ & $0,03 \mathrm{Bb}$ & $0,03 \mathrm{Ba}$ & $0,04 \mathrm{Aa}$ \\
\hline Refrigerado com Vácuo & $0,05 \mathrm{Aa}$ & $0,04 \mathrm{Bb}$ & $0,03 \mathrm{Cb}$ & $0,03 \mathrm{Ca}$ & $0,03 \mathrm{Cb}$ \\
\hline \multirow[t]{2}{*}{ Congelado sem Vácuo } & $0,05 \mathrm{Aa}$ & $0,05 \mathrm{Aa}$ & $0,04 \mathrm{Aa}$ & $0,03 \mathrm{Ba}$ & $0,04 \mathrm{Ba}$ \\
\hline & \multicolumn{5}{|c|}{ Ratio } \\
\hline Refrigerado sem Vácuo & $96,44 \mathrm{Ba}$ & $162,15 \mathrm{Aa}$ & $170,80 \mathrm{Aa}$ & $116,73 \mathrm{Ba}$ & $94,44 \mathrm{Bb}$ \\
\hline Refrigerado com Vácuo & $96,61 \mathrm{Ca}$ & $118,54 \mathrm{Cb}$ & $197,40 \mathrm{Aa}$ & $145,08 \mathrm{Ba}$ & $147,51 \mathrm{Ba}$ \\
\hline \multirow[t]{2}{*}{ Congelado sem Vácuo } & $96,61 \mathrm{Ba}$ & $92,02 \mathrm{Bb}$ & $126,15 \mathrm{Ab}$ & $143,19 \mathrm{Aa}$ & $120,81 \mathrm{Bb}$ \\
\hline & \multicolumn{5}{|c|}{ Croma } \\
\hline Refrigerado sem Vácuo & $18,69 \mathrm{Aa}$ & $16,89 \mathrm{Aa}$ & $17,99 \mathrm{Aa}$ & $17,18 \mathrm{Aa}$ & $18,24 \mathrm{Aa}$ \\
\hline Refrigerado com Vácuo & $18,39 \mathrm{Aa}$ & $17,54 \mathrm{Aa}$ & $17,46 \mathrm{Aa}$ & $18,86 \mathrm{Aa}$ & $19,02 \mathrm{Aa}$ \\
\hline \multirow[t]{2}{*}{ Congelado sem Vácuo } & $18,73 \mathrm{Aa}$ & $17,80 \mathrm{Aa}$ & $17,60 \mathrm{Aa}$ & $12,92 \mathrm{Bb}$ & $13,16 \mathrm{Bb}$ \\
\hline & \multicolumn{5}{|c|}{ Ângulo hue $\left(^{\circ}\right)$} \\
\hline Refrigerado sem Vácuo & $53,38 \mathrm{Aa}$ & $51,09 \mathrm{Aa}$ & $52,99 \mathrm{Aa}$ & $55,59 \mathrm{Aa}$ & $53,27 \mathrm{Ab}$ \\
\hline Refrigerado com Vácuo & $50,86 \mathrm{Ba}$ & $48,09 \mathrm{Ba}$ & $49,75 \mathrm{Ba}$ & $50,13 \mathrm{Ba}$ & $61,35 \mathrm{Aa}$ \\
\hline \multirow[t]{2}{*}{ Congelado sem Vácuo } & $52,35 \mathrm{Aa}$ & $48,30 \mathrm{Aa}$ & $52,13 \mathrm{Aa}$ & $56,87 \mathrm{Aa}$ & $52,67 \mathrm{Ab}$ \\
\hline & \multicolumn{5}{|c|}{ Tempo para a cocção (minutos) } \\
\hline Refrigerado sem Vácuo & $29,97 \mathrm{Aa}$ & $29,97 \mathrm{Aa}$ & $29,67 \mathrm{Aa}$ & $29,67 \mathrm{Aa}$ & $29,97 \mathrm{Aa}$ \\
\hline Refrigerado com Vácuo & $29,97 \mathrm{Aa}$ & $30,00 \mathrm{Aa}$ & $29,97 \mathrm{Aa}$ & $24,33 \mathrm{Bb}$ & $29,97 \mathrm{Aa}$ \\
\hline Congelado sem Vácuo & $30,00 \mathrm{Aa}$ & $29,97 \mathrm{Aa}$ & $29,97 \mathrm{Aa}$ & $26,00 \mathrm{Bb}$ & $29,67 \mathrm{Aa}$ \\
\hline
\end{tabular}

Os valores de croma (Tabela 2) variaram entre 12,92 e 19,02. O croma define a intensidade de cor, ou seja, valores próximos a zero são indicativos de cores neutras (branco e/ou cinza), e valores ao redor de 60 indicam cores vívidas e/ou intensas. As cores mais intensas da mandioca foram observadas nas raízes submetidas aos tratamentos refrigerados com e sem vácuo. Os menores valores foram observados nas raízes de mandioca congeladas aos 21 e 28 dias de armazenamento, provavelmente devido à presença visível de uma película de gelo sobre a amostra no momento da análise.

O menor ângulo hue $(48,09)$ foi no produto mantido sob vácuo aos sete dias de armazenamento. O maior valor foi no mesmo produto aos 28 dias de armazenamento. Valores mais próximos de 0 응 representam tonalidades mais próximas ao vermelho, enquanto valores próximos a $90^{\circ}$ representam raízes mais amarelas. Dessa forma, pode-se considerar que, durante todo o armazenamento, as raízes mantiveramse com a coloração rosada, estando relacionada à presença de licopeno nas raízes (Carvalho et al., 2011), que é um antioxidante que auxilia no combate ao envelhecimento precoce e na prevenção do câncer de próstata (Shami \& Moreira, 2004).

O tempo para a cocção das raízes variou entre 24,33 e 30,00 minutos com média geral de 29,27 minutos (Tabela 1). Raízes de mandioca orgânica da variedade BRS Dourada, minimamente processadas, mantidas durante 36 dias de armazenamento, apresentaram aumento no tempo para a cocção, porém não ultrapassaram 18,60 minutos (Oliveira et al., 2009). Neste trabalho, a variação dos valores de tempo para a cocção que ocorreram em alguns 
tratamentos, pode ser devido à característica intrínseca da amostra, relacionada ao período de colheita, que foi realizada em uma época do ano em que há a retomada de crescimento vegetativo das plantas de mandioca na região, à custa das reservas das raízes.

Diferenças significativas foram observadas no tempo para a cocção das raízes de mandioca minimamente processadas, em função dos períodos de armazenamento, variando de 24,85 a 27,70 minutos (Bezerra et al., 2002). Essa variação enquadra-se na faixa de tempos obtidos neste estudo, ambos situando-se no limite aceitável para a comercialização de mandioca de mesa, que é de 30 minutos (Lorenzi, 1994; Fukuda et al., 2002).

O percentual dos elementos que compõem a raiz de mandioca pode diferir substancialmente de uma cultivar para outra, resultando em diferenças singulares, relacionadas tanto às características próprias como gosto, tempo de cozimento, modo de uso e processo de armazenamento, como ao aspecto nutricional e farmacológico, em função da composição química apresentada por cada variedade (lulianelli \& Tavares, 2011). O menor tempo para a cocção
(Tabela 2) ocorreu na amostra acondicionada sob vácuo, mantida sob refrigeração, e nas amostras congeladas aos 21 dias de armazenamento. O maior tempo para a cocção foi apresentado pelas raízes logo após o processamento e na amostra acondicionada sob vácuo, mantida sob refrigeração, aos sete dias de armazenamento. Apesar de Favaro (2003) afirmar que os fatores responsáveis pelas características de cozimento de mandioca não estão suficientemente esclarecidos, sugere-se que este comportamento esteja relacionado a características da matéria-prima.

Após o processamento mínimo, as raízes apresentaram contagem total de aeróbios mesófilos de $5,6 \times 10^{2} \mathrm{UFC} / \mathrm{g}$ (Tabela 3), sendo uma contagem baixa para um produto que não sofreu nenhum tratamento térmico durante o processamento. Durante todo 0 armazenamento, 0 produto congelado apresentou a menor contagem de aeróbios mesófilos, sendo que aos 28 dias de armazenamento o produto apresentou baixa contagem $\left(2,6 \times 10^{2}\right)$. O produto mantido sob refrigeração, com e sem vácuo, apresentou contagem significativamente mais elevada $\left(10^{5}\right)$ para estes microrganismos.

Tabela 3 - Valores médios das análises microbiológicas em raízes da cultivar de mandioca BRS 400 (polpa rosada) minimamente processada, submetida a diferentes tratamentos. Average values of microbiological analysis in roots of cassava cultivar BRS 400 (rosy pulp) minimally processed under different treatments.

\begin{tabular}{|c|c|c|c|c|c|}
\hline \multirow{3}{*}{ Tratamentos } & \multicolumn{5}{|c|}{ Dias de Armazenamento } \\
\hline & 0 & 7 & 14 & 21 & 28 \\
\hline & \multicolumn{5}{|c|}{ Contagem total de aeróbios mesófilos (UFC/g) } \\
\hline Refrigerado sem Vácuo & $5,6 \times 10^{2}$ & $6,3 \times 10^{3}$ & $3,9 \times 10^{4}$ & $2,0 \times 10^{5}$ & $2,4 \times 10^{5}$ \\
\hline Refrigerado com Vácuo & $5,6 \times 10^{2}$ & $1,3 \times 10^{3}$ & $4,4 \times 10^{3}$ & $2,4 \times 10^{5}$ & $2,4 \times 10^{5}$ \\
\hline \multirow[t]{2}{*}{ Congelado sem Vácuo } & $6 \times 10^{2}$ & $3,1 \times 10^{2}$ & $2,6 \times 10^{2}$ & $2,8 \times 10^{2}$ & $2,6 \times 10^{2}$ \\
\hline & \multicolumn{5}{|c|}{ Contagem total de psicrotróficos (UFC/g) } \\
\hline Refrigerado sem Vácuo & $4,6 \times 10^{1}$ est & $1,4 \times 10^{3}$ & $2,4 \times 10^{5}$ & $2,4 \times 10^{5}$ & $2,4 \times 10^{5}$ \\
\hline Refrigerado com Vácuo & $4,6 \times 10^{1} \mathrm{est}$ & $3,4 \times 10^{2}$ & $2,4 \times 10^{5}$ & $2,4 \times 10^{5}$ & $1,8 \times 10^{5}$ \\
\hline \multirow[t]{2}{*}{ Congelado sem Vácuo } & $4,6 \times 10^{1}$ est & $<10$ est & $<10$ est & $<10$ est & $4,3 \times 10^{1} \mathrm{est}$ \\
\hline & \multicolumn{5}{|c|}{ Contagem total de bolores e leveduras (UFC/g) } \\
\hline Refrigerado sem Vácuo & $2,1 \times 10^{2}$ est & $6,67 \times 10^{1}$ est & $8,8 \times 10^{2}$ & $6,4 \times 10^{4}$ & $1,3 \times 10^{5}$ \\
\hline Refrigerado com Vácuo & $2,1 \times 10^{2}$ est & $<10$ est & $3,0 \times 10^{2}$ & $2,5 \times 10^{3}$ & $3,5 \times 10^{4}$ \\
\hline \multirow[t]{2}{*}{ Congelado sem Vácuo } & $2,1 \times 10^{2}$ est & $<10$ est & $0,6 \times 10^{1}$ est & $<10$ est & $1,6 \times 10^{1}$ est \\
\hline & \multicolumn{5}{|c|}{ Coliformes totais $(\mathrm{NMP} / \mathrm{g})$} \\
\hline Refrigera & $2,4 \times 10^{2}$ & $4,6 \times 10^{2}$ & $0,36 \times 10^{1}$ & $0,92 \times 10^{1}$ & $<0,3 \times 10^{1}$ \\
\hline Refrigerado com Vácuo & $2,4 \times 10^{2}$ & $0,36 \times 10^{1}$ & $0,3 \times 10^{1}$ & $2,4 \times 10^{2}$ & $1,1 \times 10^{3}$ \\
\hline \multirow[t]{2}{*}{ Congelado sem Vácuo } & $2,4 \times 10^{2}$ & $<0,3 \times 10^{1}$ & $0,36 \times 10^{1}$ & $0,36 \times 10^{1}$ & $0,36 \times 10^{1}$ \\
\hline & \multicolumn{5}{|c|}{ Coliformes termotolerantes (NMP/g) } \\
\hline Refri & $3 \times 10^{1}$ & $<0,3 \times 10^{1}$ & $<0,3 \times 10^{1}$ & $<0,3 \times 10^{1}$ & $<0,3 \times 10^{1}$ \\
\hline Refrigera & $<0,3 \times 10^{1}$ & $<0,3 \times 10^{1}$ & $<0,3 \times 10^{1}$ & $<0,3 \times 10^{1}$ & $<0,3 \times 10^{1}$ \\
\hline Congelado sem Vácuo & $<0,3 \times 10^{1}$ & $<0,3 \times 10^{1}$ & $<0,3 \times 10^{1}$ & $<0,3 \times 10^{1}$ & $<0,3 \times 10^{1}$ \\
\hline
\end{tabular}

A contagem total de psicrotróficos foi inicialmente de 4,6 $\times 10^{1}$, atingindo $2,4 \times 10^{5}$ nos tratamentos mantidos sob refrigeração com e sem vácuo, a partir de 14 dias de armazenamento. As raízes congeladas apresentaram baixas contagens durante todo o período. $\mathrm{Na}$ legislação brasileira, não há padrão para estes microrganismos em alimentos, porém em quantidades elevadas são completamente indesejáveis, considerando que o alimento pode estar estragado, com perda real ou potencial das qualidades sensoriais, comprometimento da aparência do alimento e presença de microrganismos patogênicos e/ou deterioradores (Caruso \& Camargo, 1984).

Para bolores e leveduras, todos os tratamentos apresentaram baixa contagem $\left(10^{2}\right)$ até os 14 dias de armazenamento. A partir deste período, o 
produto mantido sob refrigeração apresentou valores inaceitáveis até o final do armazenamento. $O$ produto congelado apresentou baixa contagem de bolores e leveduras durante todo 0 armazenamento. A Resolução RDC no 12, de 2 de janeiro de 2001 (Brasil, 2001), prevê o limite de $10^{3}$ UFC/g para a segurança de alimentos, sendo que as raízes congeladas corresponderam ao desejado durante todo o período.

A presença de coliformes totais ficou entre $<0,3 \times 10^{1}$ e $1,1 \times 10^{3}$, sendo que o maior valor de coliformes totais ocorreu no produto mantido sob vácuo, aos 28 dias de armazenamento, sugerindo que a embalagem não manteve a concentração gasosa desejada durante o armazenamento, permitindo o desenvolvimento de microrganismos aeróbios em seu interior. A contagem de coliformes termotolerantes foi baixa, com valor máximo de $<0,3 \times 10^{1}$, atendendo às exigências da Resolução RDC no 12 , de 2 de janeiro de 2001 (Brasil, 2001). Resultado semelhante foi obtido por Costa (2005) em raízes de mandioca in natura e minimamente processadas. De maneira geral, o produto mantido sob congelamento apresentou-se microbiologicamente aceitável durante os 28 dias de armazenamento. O mesmo não ocorreu com os demais tratamentos que apresentaram contagem elevada de aeróbios psicrotróficos aos 14 dias e aeróbios mesófilos aos 21 dias de armazenamento.

\section{Cultivar de mandioca com raízes de coloração amarela BRS 399}

Para a cultivar de mandioca com coloração da polpa das raízes amarela (BRS 399), os valores de sólidos solúveis variaram entre 3,50 Brix e 6,70 Brix, com valor médio de 4,49 Brix (Tabela 4), não havendo efeito significativo dos tratamentos e período de armazenamento sobre essa variável. Os valores do ângulo hue variaram entre 68,59 e 81,05, com valor médio de 75,71 (Tabela 4), não tendo sido detectadas diferenças significativas durante o período de armazenamento e os tratamentos. Os resultados obtidos para esta variável comprovam que as raízes de mandioca apresentaram coloração amarela e que não ocorreu mudança significativa durante 0 armazenamento.

Tabela 4 - Resumo da análise de variância com indicação dos graus de liberdade (GL), quadrados médios (QM) e coeficientes de variação (CVs) dos caracteres $\mathrm{pH}$, sólidos solúveis em ํㅜㅅㅣ (SS), acidez titulável em $\mathrm{g}$ de ácido cítrico em 100 gramas de matéria fresca $(A T)$, ratio, luminosidade $\left(L^{\#}\right)$, croma, ângulo hue $\left(^{\circ}\right)$ e tempo para a cocção (TC), avaliados em raízes de mandioca da cultivar (BRS 399) minimamente processadas, submetidas ao tratamento refrigerado sem vácuo, refrigerado com vácuo e congelamento sem vácuo, e armazenamento a $-18^{\circ} \mathrm{C}$, em função dos dias de armazenamento. Summary of analysis of variance indicating the degrees of freedom (DF), mean squares (QM) and coefficients of variation (CV) of characters $p H$, Brix soluble solids (SS), titratable acidity in $\mathrm{g}$ citric acid in 100 grams of fresh matter (AT), ratio, luminosity ( $\mathrm{L}^{\#)}$, chroma, hue angle ( $\left.{ }^{\circ}\right)$ and time for cooking (TC) evaluated in yellow cassava roots BRS 399 minimally processed subjected to cold treatments without vacuum, cooled vacuum and non-vacuum freezing and storage $-18^{\circ} \mathrm{C}$, a function of days of storage.

\begin{tabular}{lccccccccc}
\hline \multirow{2}{*}{ Fontes de Variação } & $\mathrm{GL}$ & \multicolumn{10}{c}{$\mathrm{QM}$} \\
\cline { 2 - 10 } & & $\mathrm{pH}$ & $\mathrm{SS}$ & $\mathrm{AT}$ & Ratio & $\mathrm{L}^{\#}$ & Croma & Ângulo hue & TC \\
\hline Tratamentos (T) & 2 & $0,64^{*}$ & 0,31 & $0,004^{*}$ & $9435^{*}$ & $31,45^{*}$ & $64,47^{*}$ & 3,78 & $5,23^{*}$ \\
Armazenamento (A) & 4 & $0,13^{*}$ & 0,22 & 0,0001 & $922^{*}$ & 2,65 & 7,28 & 19,30 & $141^{*}$ \\
Tx A & 8 & $0,08^{*}$ & 1,56 & $0,0005^{*}$ & $2086^{*}$ & 5,18 & $28,63^{*}$ & 17,40 & $9,62^{*}$ \\
Resíduo & 30 & 0,0004 & 0,95 & 0,0004 & 318 & 3,48 & 11,35 & 10,04 & 0,29 \\
\hline Média & - & 6,30 & 4,49 & 5,96 & 81,85 & 85,42 & 29,49 & 75,71 & 27,74 \\
CV (\%) & - & 0,10 & 21,67 & 11,05 & 21,80 & 2,18 & 11,42 & 4,19 & 1,94 \\
\hline
\end{tabular}

${ }^{*}$ Significativo a $5 \%$ de probabilidade de erro, pelo teste F.

Nas raízes de mandioca com coloração amarela da cultivar BRS 399, ocorreu aumento significativo do $\mathrm{pH}$ (Tabela 5) ao longo do armazenamento, nos tratamentos apenas refrigerado e no embalado a vácuo mantidos sob refrigeração. No produto congelado, ocorreu redução com pequenas oscilações a partir de 14 dias de armazenamento. Apesar da diferença estatística, pode-se observar que os valores de $\mathrm{pH}$ se situaram entre 5,96 e 6,73, podendo ser considerado um produto de baixa aci- dez. O aumento nos valores de $\mathrm{pH}$ ao longo do armazenamento nos tratamentos apenas refrigerados, provavelmente, corresponde ao maior consumo dos ácidos orgânicos no processo respiratório, e a atividade microbiana no produto ocorrida durante o período, conforme apresentado na Tabela 6. De acordo com Barry-Ryan \& O'beirne (2008), a elevação do $\mathrm{pH}$ em produtos minimamente processados é atribuída ao aumento da carga microbiana durante o armazenamento. 
Tabela 5 - Valores médios(@) de pH, acidez titulável, ratio, luminosidade, croma e tempo para a cocção em raízes de mandioca da cultivar BRS 399 minimamente processadas, submetidas a diferentes tratamentos. Average values of $\mathrm{pH}$, titratable acidity, ratio, brightness, chroma and time for cooking in roots of yellow cassava BRS 399 minimally processed under different treatments.

\begin{tabular}{|c|c|c|c|c|c|}
\hline \multirow{3}{*}{ Tratamentos } & \multicolumn{5}{|c|}{ Dias de armazenamento } \\
\hline & 0 & 7 & 14 & 21 & 28 \\
\hline & \multicolumn{5}{|c|}{$\mathrm{pH}$} \\
\hline Refrigerado sem Vácuo & $6,17 \mathrm{Ca}$ & $6,17 \mathrm{Cb}$ & $6,34 \mathrm{Bb}$ & $6,33 \mathrm{Bb}$ & $6,66 \mathrm{Ab}$ \\
\hline Refrigerado com Vácuo & $6,17 \mathrm{Ea}$ & $6,40 \mathrm{Da}$ & $6,45 \mathrm{Ca}$ & $6,66 \mathrm{Ba}$ & $6,73 \mathrm{Aa}$ \\
\hline \multirow[t]{2}{*}{ Congelado sem Vácuo } & $6,17 \mathrm{Aa}$ & $6,14 \mathrm{Bc}$ & $6,04 \mathrm{Dc}$ & $5,96 \mathrm{Ec}$ & $6,06 \mathrm{Cc}$ \\
\hline & \multicolumn{5}{|c|}{ Acidez titulável (g de ácido cítrico/100 g de matéria fresca) } \\
\hline Refrigerado sem Vácuo & $0,05 \mathrm{Ba}$ & $0,07 \mathrm{Ab}$ & $0,05 \mathrm{Bb}$ & $0,07 \mathrm{Aa}$ & $0,05 \mathrm{Bb}$ \\
\hline Refrigerado com Vácuo & $0,06 \mathrm{Aa}$ & $0,05 \mathrm{Ac}$ & $0,04 \mathrm{Bb}$ & $0,03 \mathrm{Bb}$ & $0,04 \mathrm{Bb}$ \\
\hline \multirow[t]{2}{*}{ Congelado sem Vácuo } & $0,06 \mathrm{Ba}$ & $0,08 \mathrm{Aa}$ & $0,09 \mathrm{Aa}$ & $0,08 \mathrm{Aa}$ & $0,08 \mathrm{Aa}$ \\
\hline & \multicolumn{5}{|c|}{ Ratio } \\
\hline Refrigerado sem Vácuo & $75,80 \mathrm{Aa}$ & $71,62 \mathrm{Ab}$ & $104,64 \mathrm{Aa}$ & $71,21 \mathrm{Ab}$ & $71,73 \mathrm{Ab}$ \\
\hline Refrigerado com Vácuo & $64,80 \mathrm{Ca}$ & $100,97 \mathrm{Ba}$ & $105,16 \mathrm{Ba}$ & $166,97 \mathrm{Aa}$ & $103,26 \mathrm{Ba}$ \\
\hline \multirow[t]{2}{*}{ Congelado sem Vácuo } & $75,80 \mathrm{Aa}$ & $47,72 \mathrm{Ab}$ & $54,84 \mathrm{Ab}$ & $49,64 \mathrm{Ab}$ & $63,57 \mathrm{Ab}$ \\
\hline & \multicolumn{5}{|c|}{ Luminosidade $\left(\mathrm{L}^{\#)}\right.$} \\
\hline Refrigerado sem Vácuo & $85,06 \mathrm{Aa}$ & $86,51 \mathrm{Aa}$ & $87,00 \mathrm{Aa}$ & $87,06 \mathrm{Aa}$ & $84,99 \mathrm{Aa}$ \\
\hline Refrigerado com Vácuo & $86,67 \mathrm{Aa}$ & $86,08 \mathrm{Aa}$ & $85,57 \mathrm{Aa}$ & $86,73 \mathrm{Aa}$ & $86,85 \mathrm{Aa}$ \\
\hline \multirow[t]{2}{*}{ Congelado sem Vácuo } & $85,89 \mathrm{Aa}$ & $84,84 \mathrm{Aa}$ & $81,32 \mathrm{Ab}$ & $83,33 \mathrm{Ab}$ & $83,39 \mathrm{Aa}$ \\
\hline & \multicolumn{5}{|c|}{ Croma } \\
\hline Refrigerado sem Vácuo & $31,03 \mathrm{Aa}$ & $26,75 \mathrm{Aa}$ & $27,91 \mathrm{Aa}$ & $30,01 \mathrm{Aa}$ & $31,64 \mathrm{Aa}$ \\
\hline Refrigerado com Vácuo & $31,92 \mathrm{Aa}$ & $28,89 \mathrm{Aa}$ & $30,79 \mathrm{Aa}$ & $32,17 \mathrm{Aa}$ & $34,12 \mathrm{Aa}$ \\
\hline \multirow[t]{2}{*}{ Congelado sem Vácuo } & $26,12 \mathrm{Ba}$ & $28,59 \mathrm{Aa}$ & $31,73 \mathrm{Aa}$ & $28,81 \mathrm{Aa}$ & $21,90 \mathrm{Bb}$ \\
\hline & \multicolumn{5}{|c|}{ Tempo para a cocção (minutos) } \\
\hline Refrigerado sem Vácuo & $29,97 \mathrm{Aa}$ & $29,97 \mathrm{Aa}$ & $29,97 \mathrm{Aa}$ & $17,97 \mathrm{Bb}$ & $30,00 \mathrm{Aa}$ \\
\hline Refrigerado com Vácuo & $30,00 \mathrm{Aa}$ & $29,97 \mathrm{Aa}$ & $30,00 \mathrm{Aa}$ & $22,00 \mathrm{Ba}$ & $30,00 \mathrm{Aa}$ \\
\hline Congelado sem Vácuo & $29,97 \mathrm{Aa}$ & $24,97 \mathrm{Cb}$ & $29,97 \mathrm{Aa}$ & $22,33 \mathrm{Da}$ & $29,00 \mathrm{Bb}$ \\
\hline
\end{tabular}

(@) Médias de uma mesma variável, seguidas pela mesma letra maiúscula na linha e minúscula na coluna, não diferem entre si, a $5 \%$ de probabilidade de erro, pelo teste de agrupamento de médias de Scott e Knott.

As raízes congeladas apresentaram maiores valores de acidez titulável durante o armazenamento, não diferindo significativamente apenas do produto mantido sob refrigeração aos 21 dias de armazenamento. $\mathrm{O}$ aumento na acidez de produtos armazenados por curtos períodos pode ser explicado pela geração de radicais (ácidos galacturônicos) a partir da hidrólise dos constituintes da parede celular, em especial as pectinas (Senter et al., 1991). A manutenção dos maiores valores de acidez titulável no produto mantido sob congelamento, provavelmente, é devida à menor atividade metabólica e microbiana ocorrida neste produto durante o armazenamento, conforme apresentado na Tabela 6 , uma vez que os valores de $\mathrm{pH}$ das raízes são propícios ao desenvolvimento de microrganismos. As amostras mantidas sob vácuo apresentaram os menores valores de acidez titulável, ao contrário do que era esperado, uma vez que o processo de vácuo deveria manter de forma mais efetiva as características iniciais da amostra quando comparado ao mesmo produto mantido somente sob refrigeração.

Os valores de ratio oscilaram entre 47,72 e 166,97. Os maiores valores foram obtidos nas amostras acondicionadas sob vácuo mantidas sob refrigeração, e os menores, nas amostras mantidas congeladas (Tabela 5). A partir do sétimo dia até o final do armazenamento, as amostras mantidas sob vácuo apresentaram os maiores valores de ratio, correspondendo ao comportamento apresentado pelos sólidos solúveis e acidez titulável das amostras.

Os valores de $L^{\#}$ variaram entre 81,32 e 87,06 , ocorrendo diferença significativa apenas aos 14 e 21 dias de armazenamento no produto congelado, que apresentou valores significativamente inferiores aos demais tratamentos. Esses resultados 
revelam que as amostras congeladas nestes períodos de análise se apresentavam mais escurecidas, ou seja, com menor luminosidade, o que visualmente não foi observado, uma vez que o menor valor de $L^{*}$ foi de 81,32 . De maneira geral, não ocorreu escurecimento nas raízes de mandioca minimamente processadas submetidas aos diferentes tratamentos durante todo o armazenamento.

Os valores de croma apresentaram diferença apenas nas raízes congeladas. No início e aos 28 dias de armazenamento, os valores foram significativamente menores que nos demais dias de análise. Esses resultados, provavelmente, correspondem às características intrínsecas da amostra e, provavelmente, devido à película de gelo existente sobre as amostras no momento da análise. Com os dados obtidos, é possível afirmar que não ocorreu alteração significativa na intensidade da cor das raízes de mandioca durante o armazenamento.

O tempo para a cocção das raízes (Tabela 5) variou entre 17,97 e 30,00 minutos, com valor médio de 27,74 minutos (Tabela 4). Aos 21 dias de armazenamento, o produto mantido em todos os tratamentos apresentou tempo de cozimento inferior aos demais dias de análise, provavelmente devido às características intrínsecas das amostras. $\mathrm{O}$ produto congelado apresentou oscilação no tempo para a cocção durante todo o armazenamento, com variação entre 22,33 minutos e 29,97 minutos. Nas raízes de mandioca com boas características sensori- ais, o cozimento é rápido e uniforme, e há poucas fibras. Estas características estão associadas ao genótipo, às condições ambientais favoráveis e à idade da planta (Lorenzi, 2003). Moreto \& Neubert (2014) avaliaram quatro variedades de mandioca de mesa quanto ao tempo de cozimento, em função da época de colheita, e concluíram que o tempo de cozimento foi fortemente influenciado pela época de avaliação, em que épocas distintas de melhor e pior cozimento das raízes puderam ser observadas. De acordo com os mesmos autores, o pico de pior cozimento ocorreu no mês de novembro, coincidindo com os piores teores de amido e com a fase de intenso processo de rebrotamento e crescimento vegetativo das plantas. $O$ trabalho apresentado foi realizado no mês de novembro de 2013, provavelmente justificando, segundo Moreto \& Neubert (2014), o elevado tempo para a cocção da maioria das amostras avaliadas.

A contagem total de aeróbios mesófilos foi de $8,0 \times 10^{2} \mathrm{UFC} / \mathrm{g}$ (Tabela 6) após o processamento mínimo, sendo considerada uma contagem baixa para produtos minimamente processados. O produto congelado apresentou baixas contagens destes microrganismos com redução dos mesmos aos $14 \mathrm{e}$ 21 dias de armazenamento e contagem de $3,0 \times 10^{2}$ aos 28 dias de armazenamento. Para o produto apenas refrigerado com e sem vácuo, as contagens foram mais altas, atingindo $\left(10^{5}\right)$ aos 21 dias de armazenamento.

Tabela 6 - Valores médios das análises microbiológicas em raízes de mandioca da cultivar BRS 399 minimamente processadas, submetidas a diferentes tratamentos. Average values of the microbiological analyzes in yellow cassava roots BRS 399 minimally processed under different treatments.

\begin{tabular}{|c|c|c|c|c|c|}
\hline \multirow{3}{*}{ Tratamentos } & \multicolumn{5}{|c|}{ Dias de armazenamento } \\
\hline & 0 & 7 & 14 & 21 & 28 \\
\hline & \multicolumn{5}{|c|}{ Contagem total de aeróbios mesófilos (UFC/g) } \\
\hline Refrigerado sem Vácuo & $8,0 \times 10^{2}$ & $4,3 \times 10^{4}$ & $5,4 \times 10^{4}$ & $2,4 \times 10^{5}$ & $2,3 \times 10^{5}$ \\
\hline Refrigerado com Vácuo & $8,0 \times 10^{2}$ & $1,4 \times 10^{3}$ & $9,9 \times 10^{4}$ & $2,4 \times 10^{5}$ & $1,2 \times 10^{5}$ \\
\hline \multirow{2}{*}{ Congelado sem Vácuo } & $8,0 \times 10^{2}$ & $2,9 \times 10^{2}$ & $6,3 \times 10^{1}$ est & $2,1 \times 10^{1}$ est & $3,0 \times 10^{2}$ \\
\hline & \multicolumn{5}{|c|}{ Contagem total de psicrotróficos (UFC/g) } \\
\hline Refrigerado sem Vácuo & $10 \times 10^{1} \mathrm{est}$ & $2,3 \times 10^{5}$ & $2,4 \times 10^{5}$ & $2,4 \times 10^{5}$ & $2,3 \times 10^{5}$ \\
\hline Refrigerado com Vácuo & $10 \times 10^{1} \mathrm{est}$ & $2,0 \times 10^{5}$ & $2,4 \times 10^{5}$ & $2,4 \times 10^{5}$ & $2,2 \times 10^{5}$ \\
\hline \multirow[t]{2}{*}{ Congelado sem Vácuo } & $10 \times 10^{1} \mathrm{est}$ & $1,6 \times 10^{1} \mathrm{est}$ & $<10$ est & $1,0 \times 10^{1}$ est & $11 \times 10$ est \\
\hline & \multicolumn{5}{|c|}{ Contagem total de bolores e leveduras (UFC/g) } \\
\hline Refrigerado sem Vácuo & $3,4 \times 10^{2}$ & $6,2 \times 10^{3}$ & $1,4 \times 10^{5}$ & $1,6 \times 10^{5}$ & $9,4 \times 10^{4}$ \\
\hline Refrigerado com Vácuo & $3,4 \times 10^{2}$ & $2,6 \times 10^{2}$ & $1,4 \times 10^{5}$ & $3,9 \times 10^{3}$ & $1,0 \times 10^{5}$ \\
\hline \multirow[t]{2}{*}{ Congelado sem Vácuo } & $3,4 \times 10^{2}$ & $0,6 \times 10^{1}$ est & $0,3 \times 10^{1}$ est & $0,6 \times 10^{1}$ est & $3 \times 10^{1}$ est \\
\hline & \multicolumn{5}{|c|}{ Coliformes totais $(\mathrm{NMP} / \mathrm{g})$} \\
\hline Refrigerado sem Vácuo & $4,6 \times 10^{2}$ & $>1,1 \times 10^{3}$ & $0,3 \times 10^{1}$ & $>1,1 \times 10^{3}$ & $0,61 \times 10^{1}$ \\
\hline Refrigerado com Vácuo & $4,6 \times 10^{2}$ & $1,1 \times 10^{3}$ & $0,61 \times 10^{1}$ & $>1,1 \times 10^{3}$ & $4,3 \times 10^{1}$ \\
\hline \multirow[t]{2}{*}{ Congelado sem Vácuo } & $4,6 \times 10^{2}$ & $9,3 \times 10^{1}$ & $<0,3 \times 10^{1}$ & $1,1 \times 10^{1}$ & $0,74 \times 10^{1}$ \\
\hline & \multicolumn{5}{|c|}{ Coliformes termotolerantes $(\mathrm{NMP} / \mathrm{g})$} \\
\hline Refrigerado sem Vácuo & $<0,3 \times 10^{1}$ & $<0,3 \times 10^{1}$ & $<0,3 \times 10^{1}$ & $<0,3 \times 10^{1}$ & $<0,3 \times 10^{1}$ \\
\hline Refrigerado com Vácuo & $<0,3 \times 10^{1}$ & $<0,3 \times 10^{1}$ & $<0,3 \times 10^{1}$ & $<0,3 \times 10^{1}$ & $<0,3 \times 10^{1}$ \\
\hline Congelado sem Vácuo & $<0,3 \times 10^{1}$ & $<0,3 \times 10^{1}$ & $<0,3 \times 10^{1}$ & $<0,3 \times 10^{1}$ & $<0,3 \times 10^{1}$ \\
\hline
\end{tabular}


Nas raízes congeladas, ocorreram baixas contagens de psicrotróficos durante todo o armazenamento, sendo o produto aceitável de acordo com literatura já citada neste trabalho. A contagem inicial foi de $10 \times 10^{1}$ atingindo $2,3 \times 10^{5}$ no tratamento mantido sob refrigeração sem vácuo e $2,0 \times 10^{5}$ no produto com vácuo a partir de sete dias de armazenamento.

Para bolores e leveduras, as raízes congeladas também apresentaram contagem aceitável durante todo o período de estudo (Brasil, 2001). O mesmo não ocorreu com os demais tratamentos, que apresentaram contagens elevadas a partir de 14 dias de armazenamento, com exceção do produto mantido sob vácuo, aos 21 dias de armazenamento.

Os valores de coliformes totais foram baixos durante todo o armazenamento do produto mantido congelado, demonstrando a eficiência do método no controle de microrganismos. O mesmo não ocorreu com os demais tratamentos, que apresentaram oscilações com maiores valores nos tratamentos mantidos sob refrigeração com e sem vácuo, aos sete e 21 dias de armazenamento. As exigências da Resolução RDC № 12, de 2 de janeiro de 2001 (Brasil, 2001), é de, no máximo, $5 \times 10^{2}$ para coliformes a $45^{\circ} \mathrm{C}$, em frutas frescas in natura, preparadas (descascadas ou selecionadas ou fracionadas) sanificadas, refrigeradas ou congeladas, para consumo direto. A contagem de coliformes termotolerantes obtida no experimento foi bem inferior ao limite estabelecido, demonstrando que o produto estava em perfeitas condições de consumo para este tipo de microrganismo. Silva (2009) encontrou variação entre $<3$ e $1,1 \times 10^{3} \mathrm{NMP} / \mathrm{g}$ para coliformes totais e valores $<3 \mathrm{NMP} / \mathrm{g}$ para coliformes termotolerantes em mandioca minimamente processada, mantida sob refrigeração.
Para esta variedade, o tratamento em que as raízes de mandioca minimamente processadas foram mantidas congeladas, a contagem microbiana apresentou-se aceitável durante os 28 dias de armazenamento, sendo um indicativo de que este tratamento é adequado para o aumento da vida útil do produto.

\section{Cultivar de mandioca com raízes de coloração creme IAC 576-70}

Para a cultivar de mandioca com coloração das raízes creme IAC 576-70, os valores de luminosidade $\left(L^{*}\right)$ variaram entre 77,61 e 90,51 , com valor médio de 87,28 (Tabela 7), não havendo efeito significativo dos tratamentos e período de armazenamento sobre essa variável. Os valores do ângulo hue variaram entre 75,26 e 83,94 , com valor médio de 80,05 (Tabela 7), não tendo sido detectadas diferenças significativas durante o período de armazenamento e os tratamentos. Valores de ângulo hue de $90^{\circ}$ significa que 0 produto tem coloração creme/amarelada.

Para o pH aos 28 dias de armazenamento, os valores foram significativamente superiores aos demais dias de análise (Tabela 8). Nos demais dias de análise, em todos os tratamentos ocorreram oscilações nos valores desta variável, com exceção do produto mantido sobre refrigeração e congelado aos 21 dias de armazenamento e todos os tratamentos no dia zero; em todos os demais dias de análise, ocorreu diferença significativa nos valores de $\mathrm{pH}$ entre os tratamentos. O maior valor de $\mathrm{pH}$ foi nas raízes acondicionadas sob vácuo, mantidas sob refrigeração, aos 28 dias de armazenamento.

Tabela 7 - Resumo da análise de variância com indicação dos graus de liberdade (GL), quadrados médios (QM) e coeficientes de variação (CVs) dos caracteres pH, sólidos solúveis em ${ }^{\circ} B r i x(S S)$, acidez titulável em $\mathrm{g}$ de ácido cítrico em 100 gramas de matéria fresca $(\mathrm{AT})$, ratio, luminosidade $\left(\mathrm{L}^{\#}\right)$, croma, ângulo hue $\left(^{\circ}\right)$ e tempo para a cocção (TC), avaliados em raízes de mandioca da cultivar IAC 576-70 minimamente processadas, submetidas aos tratamentos refrigerado sem vácuo, refrigerado com vácuo e congelamento sem vácuo e armazenamento a $-18{ }^{\circ} \mathrm{C}$, em função dos dias de armazenamento. Summary of analysis of variance indicating the degrees of freedom (DF), mean squares (QM) and coefficients of variation (CVs) of characters $\mathrm{pH}$, Brix soluble solids (SS), titratable acidity in g citric acid in 100 grams of fresh matter (AT), ratio, luminosity ( $\left.\mathrm{L}^{\#}\right)$, chroma, hue angle $\left(^{\circ}\right)$ and time for cooking (TC), evaluated in cassava roots Cream IAC 570-70 minimally processed subjected to cold treatments without vacuum, vacuum and cooled with freezing without vacuum and storage $-18^{\circ} \mathrm{C}$, as a function of days of storage.

\begin{tabular}{|c|c|c|c|c|c|c|c|c|c|}
\hline \multirow{2}{*}{\multicolumn{2}{|c|}{ Fontes de Variação GL }} & \multicolumn{8}{|c|}{$\mathrm{QM}$} \\
\hline & & $\mathrm{pH}$ & SS & AT & Ratio & $\mathrm{L}^{\#}$ & Chroma & Ângulo hue & TC \\
\hline Tratamentos (T) & 2 & $0,06^{*}$ & $0,64^{*}$ & $0,0008^{*}$ & $1966^{*}$ & 14,27 & 13,16 & 12,31 & 3,54 \\
\hline Armazenamento (A) & 4 & $0,22^{*}$ & $12,65^{*}$ & $0,0014^{*}$ & $1635^{*}$ & 7,40 & 18,48 & 6,34 & $61,83^{*}$ \\
\hline $\mathrm{T} \times \mathrm{A}$ & 8 & $0,08^{*}$ & 0,15 & $0,0006^{*}$ & $708^{\star}$ & 7,64 & $25,13^{\star}$ & 5,00 & 3,92 \\
\hline Resíduo & 30 & 0,00005 & 0,18 & 0,00002 & 78,71 & 7,05 & 9,07 & 4,98 & 2,80 \\
\hline Média & - & 6,51 & 4,46 & 6,64 & 70,30 & 87,28 & 24,36 & 80,05 & 20,69 \\
\hline CV (\%) & - & 0,10 & 9,58 & 7,27 & 12,62 & 3,04 & 12,36 & 2,79 & 8,09 \\
\hline
\end{tabular}

"Significativo a $5 \%$ de probabilidade de erro, pelo teste $\mathrm{F}$. 
Tabela 8 - Valores médios(@) de pH, sólidos solúveis, acidez titulável, ratio, croma e tempo para a cocção em raízes de mandioca da cultivar IAC 576-70 minimamente processadas, submetidas a diferentes tratamentos. Average values of $\mathrm{pH}$, soluble solids, titratable acidity, ratio, chroma and time for cooking in cassava roots cream IAC 576-70 minimally processed under different treatments.

\begin{tabular}{|c|c|c|c|c|c|}
\hline \multirow{3}{*}{ Tratamentos } & \multicolumn{5}{|c|}{ Dias de Armazenamento } \\
\hline & 0 & 7 & 14 & 21 & 28 \\
\hline & \multicolumn{5}{|c|}{$\mathrm{pH}$} \\
\hline Refrigerado sem Vácuo & 6,34 Ea & $6,62 \mathrm{Ba}$ & $6,57 \mathrm{Ca}$ & $6,42 \mathrm{Db}$ & $6,79 \mathrm{Ab}$ \\
\hline Refrigerado com Vácuo & 6,35 Da & $6,38 \mathrm{Cb}$ & 6,25 Ec & $6,77 \mathrm{Ba}$ & 6,92 Aa \\
\hline \multirow[t]{2}{*}{ Congelado sem Vácuo } & 6,34 Ea & 6,36 Dc & $6,50 \mathrm{Bb}$ & $6,42 \mathrm{Cb}$ & $6,55 \mathrm{Ac}$ \\
\hline & \multicolumn{5}{|c|}{ Sólidos solúveis ( ${ }^{\circ}$ Brix) } \\
\hline Refrigerado sem Vácuo & 6,56 Aa & $4,00 \mathrm{Ba}$ & $3,73 \mathrm{Ba}$ & $4,20 \mathrm{Ba}$ & $3,97 \mathrm{Ba}$ \\
\hline Refrigerado com Vácuo & $6,57 \mathrm{Aa}$ & $4,10 \mathrm{Ba}$ & 4,03 Ba & 4,27 Ba & 4,23 Ba \\
\hline \multirow[t]{2}{*}{ Congelado sem Vácuo } & $6,57 \mathrm{Aa}$ & $4,13 \mathrm{Ba}$ & $3,50 \mathrm{Ba}$ & $3,47 \mathrm{Bb}$ & $3,50 \mathrm{Ba}$ \\
\hline & \multicolumn{5}{|c|}{ Acidez titulável (g de ácido cítrico/100 g de matéria fresca) } \\
\hline Refrigerado sem Vácuo & $0,08 \mathrm{Ba}$ & $0,04 \mathrm{Dc}$ & $0,06 \mathrm{Cb}$ & $0,09 \mathrm{Aa}$ & $0,03 \mathrm{Ec}$ \\
\hline Refrigerado com Vácuo & $0,08 \mathrm{Aa}$ & $0,05 \mathrm{Bb}$ & $0,08 \mathrm{Aa}$ & $0,05 \mathrm{Bc}$ & $0,05 \mathrm{Bb}$ \\
\hline \multirow[t]{2}{*}{ Congelado sem Vácuo } & $0,08 \mathrm{Aa}$ & $0,08 \mathrm{Aa}$ & $0,07 \mathrm{Aa}$ & $0,08 \mathrm{Ab}$ & $0,06 \mathrm{Ba}$ \\
\hline & \multicolumn{5}{|c|}{ Ratio } \\
\hline Refrigerado sem Vácuo & $81,42 \mathrm{Ba}$ & $86,85 \mathrm{Ba}$ & $58,58 \mathrm{Ca}$ & $46,61 \mathrm{Cb}$ & $113,02 \mathrm{Aa}$ \\
\hline Refrigerado com Vácuo & $81,43 \mathrm{Aa}$ & $79,58 \mathrm{Aa}$ & $55,17 \mathrm{Ba}$ & $83,40 \mathrm{Aa}$ & $82,93 \mathrm{Ab}$ \\
\hline \multirow[t]{2}{*}{ Congelado sem Vácuo } & $81,43 \mathrm{Aa}$ & $50,49 \mathrm{Bb}$ & $48,24 \mathrm{Ba}$ & $47,17 \mathrm{Bb}$ & $58,10 \mathrm{Bc}$ \\
\hline & \multicolumn{5}{|c|}{ Croma } \\
\hline Refrigerado sem Vácuo & $25,51 \mathrm{Aa}$ & $24,58 \mathrm{Aa}$ & $23,01 \mathrm{Aa}$ & $27,48 \mathrm{Aa}$ & $24,77 \mathrm{Aa}$ \\
\hline Refrigerado com Vácuo & $24,20 \mathrm{Aa}$ & $23,40 \mathrm{Aa}$ & $25,29 \mathrm{Aa}$ & $27,08 \mathrm{Aa}$ & $23,56 \mathrm{Aa}$ \\
\hline \multirow[t]{2}{*}{ Congelado sem Vácuo } & $25,64 \mathrm{Aa}$ & $26,96 \mathrm{Aa}$ & $26,08 \mathrm{Aa}$ & $20,72 \mathrm{Bb}$ & $17,09 \mathrm{Bb}$ \\
\hline & \multicolumn{5}{|c|}{ Tempo para a cocção (minutos) } \\
\hline Refrigerado sem Vácuo & $19,67 \mathrm{Ba}$ & $21,00 \mathrm{Ba}$ & $27,33 \mathrm{Aa}$ & $17,00 \mathrm{Ca}$ & $20,00 \mathrm{Ba}$ \\
\hline Refrigerado com Vácuo & $20,33 \mathrm{Ba}$ & $21,00 \mathrm{Ba}$ & $24,00 \mathrm{Ab}$ & $18,00 \mathrm{Ba}$ & $21,33 \mathrm{Ba}$ \\
\hline Congelado sem Vácuo & $19,97 \mathrm{Ba}$ & $20,00 \mathrm{Ba}$ & $23,33 \mathrm{Ab}$ & $18,00 \mathrm{Ba}$ & $19,33 \mathrm{Ba}$ \\
\hline
\end{tabular}

(@) Médias de uma mesma variável, seguidas pela mesma letra maiúscula na linha e minúscula na coluna, não diferem entre si, a $5 \%$ de probabilidade de erro, pelo teste de agrupamento de médias de Scott e Knott.

Os sólidos solúveis reduziram significativamente até o sétimo dia de armazenamento em todos os tratamentos, contrariando a informação de que em produtos minimamente processados geralmente ocorre acréscimo no valor de sólidos solúveis devido à perda de água do produto. A diminuição nos teores de sólidos solúveis ocorrida neste trabaIho pode ser devida a reações internas, não só catabólicas (destruição), como também anabólicas (síntese), que levam a um gasto de energia, diminuindo os teores dos mesmos (Oliveira \& Cereda, 1999). O aumento nos sólidos solúveis em alguns períodos e tratamentos pode ter ocorrido devido a variações na matéria-prima das amostras de mandioca minimamente processadas. O produto congelado apresentou os menores valores de sólidos solúveis aos 21 dias de armazenamento. Os valores de sólidos solúveis observados neste trabalho situam-se na faixa abaixo ou acima da variação de 4,0 ${ }^{\circ}$ Brix a $6,0^{\circ}$ Brix, verificada por Silva et al. (2003), o que comprova que este comportamento pode ser normal para raízes de mandioca minimamente processadas.

O produto mantido sob refrigeração apresentou o maior valor de acidez titulável aos 21 dias de armazenamento. $O$ tratamento que apresentou menor influência sobre os valores de acidez titulável foi o congelado (Tabela 8), provavelmente devido à menor ação microbiana (Tabela 9) e metabólicas no produto. A variação ocorrida em todos os tratamentos, durante o armazenamento, pode ser devido às características intrínsecas das amostras. Raízes de mandioca in natura da mesma cultivar apresentaram acidez de $1,5 \%$ na raiz (Oliveira et al., 2003), sendo significativamente superior aos valores observados neste trabalho. 
Os valores de ratio (Tabela 8) corresponderam à relação dos sólidos solúveis e da acidez titulável apresentada pelo produto, variando entre 46,61 e 113,02. De maneira geral, durante todo o armazenamento, as raízes congeladas apresentaram menores valores de ratio. De acordo com Fernandes et al. (2010), os valores da relação sólidos solúveis/acidez titulável, geralmente, são um bom indicativo do sabor, pois dão uma boa ideia do equilíbrio entre esses dois componentes.

Os valores de croma apresentaram variação significativa apenas no produto congelado aos $21 \mathrm{e}$ 28 dias de armazenamento, em que os valores foram significativamente inferiores aos demais dias e tratamentos. Visualmente, não foi observada variação significativa na cor das amostras submetidas a esse tratamento.

O tempo para a cocção foi muito bom para esta cultivar de mandioca (Tabela 8). Em todos os tratamentos e dias de análise, o produto apresentou-se em condições de cozimento, situando-se abaixo do limite de tempo para a cocção de mandioca de mesa. O tempo variou entre 17,00 e 27,33 minutos. De acordo com Moreto \& Neubert (2014), o tempo de cozimento tem grande importância no mercado de mandioca de mesa. Entre os vários fatores que afetam o tempo de cozimento, está a cultivar adotada. De acordo com os mesmos autores, o baixo tempo de cozimento gera economia de energia e de ocupação, sendo uma característica desejada pelo consumidor final. A variação no tempo de cozimento e na qualidade da massa cozida é fator inibidor para o comércio de raízes de mandioca de mesa durante todo o ano. Fukuda \& Borges (1988) afirmam que o tempo de cozimento é um caráter importante na seleção de uma cultivar de mandioca de mesa, sendo preferidas as que apresentam menores tempos de cozimento. A mesma afirmação foi realizada por Pereira et al. (1995) e Lorenzi et al. (1996). Favaro (2003) constatou diferença no tempo de cozimento entre variedades e entre época de colheita, em uma mesma variedade, sendo de mais rápido cozimento as raízes de época de colheita mais precoce.

$\mathrm{O}$ produto congelado apresentou a menor contagem total de aeróbios mesófilos, com exceção dos 21 dias de armazenamento (Tabela 9). O produto mantido sob vácuo refrigerado apresentou altas contagens a partir de 21 dias de armazenamento. As raízes mantidas sob refrigeração sem vácuo apresentaram altas contagens somente aos 28 dias de armazenamento.

Tabela 9 - Valores médios das análises microbiológicas em raízes de mandioca da cultivar IAC 576-70 minimamente processadas, submetidas a diferentes tratamentos. Average microbiological analysis in cassava roots values cream IAC 576-70 minimally processed under different treatments.

\begin{tabular}{|c|c|c|c|c|c|}
\hline \multirow{3}{*}{ Tratamentos } & \multicolumn{5}{|c|}{ Dias de Armazenamento } \\
\hline & 0 & 7 & 14 & 21 & 28 \\
\hline & \multicolumn{5}{|c|}{ Contagem total de aeróbios mesófilos (UFC/g) } \\
\hline Refrigerado sem Vácuo & $1,1 \times 10^{3}$ & $1,0 \times 10^{3}$ & $1,5 \times 10^{2}$ & $6,0 \times 10^{2}$ & $2,4 \times 10^{5}$ \\
\hline Refrigerado com Vácuo & $1,1 \times 10^{3}$ & $1,4 \times 10^{2}$ & $1,0 \times 10^{4}$ & $2,4 \times 10^{5}$ & $2,3 \times 10^{5}$ \\
\hline \multirow[t]{2}{*}{ Congelado sem Vácuo } & $1,1 \times 10^{3}$ & $7,3 \times 10^{1}$ est & $5,3 \times 10^{1}$ est & $6,3 \times 10^{4}$ & $4,1 \times 10^{2}$ \\
\hline & \multicolumn{5}{|c|}{ Contagem total de psicrotróficos (UFC/g) } \\
\hline Refrigerado sem Vácuo & $10,6 \times 10^{1}$ est & $3,4 \times 10^{2}$ & $6,2 \times 10^{2}$ & $2,4 \times 10^{5}$ & $2,3 \times 10^{5}$ \\
\hline Refrigerado com Vácuo & $10,6 \times 10^{1}$ est & $0,6 \times 10^{1}$ est & $7,2 \times 10^{4}$ & $2,4 \times 10^{5}$ & $2,2 \times 10^{5}$ \\
\hline \multirow[t]{2}{*}{ Congelado sem Vácuo } & $10,6 \times 10^{1}$ est & $<10$ est & $<10$ est & $1,9 \times 10^{3}$ & $1,3 \times 10^{3}$ \\
\hline & \multicolumn{5}{|c|}{ Contagem total de bolores e leveduras (UFC/g) } \\
\hline Refrigerado sem Vácuo & $7,1 \times 10^{2}$ & $3,3 \times 10^{1}$ est & $1,9 \times 10^{2}$ est & $5,3 \times 10^{2}$ & $7,2 \times 10^{4}$ \\
\hline Refrigerado com Vácuo & $7,1 \times 10^{2}$ & $0,6 \times 10^{1}$ est & $2,8 \times 10^{4}$ & $1,5 \times 10^{5}$ & $5,0 \times 10^{3}$ \\
\hline \multirow[t]{2}{*}{ Congelado sem Vácuo } & $7,1 \times 10^{2}$ & $<10$ est & $<10$ est & $1.0 \times 10^{1} \mathrm{est}$ & $<10$ est \\
\hline & \multicolumn{5}{|c|}{ Coliformes totais $(\mathrm{NMP} / \mathrm{g})$} \\
\hline Refrigerado sem Vácuo & $2,4 \times 10^{2}$ & $1,1 \times 10^{3}$ & $1,1 \times 10^{1}$ & $>1,1 \times 10^{3}$ & $>1,1 \times 10^{3}$ \\
\hline Refrigerado com Vácuo & $2,4 \times 10^{2}$ & $4,3 \times 10^{1}$ & $0,3 \times 10^{1}$ & $>1,1 \times 10^{3}$ & $4,6 \times 10^{2}$ \\
\hline \multirow[t]{2}{*}{ Congelado sem Vácuo } & $2,4 \times 10^{2}$ & $<0,3 \times 10^{1}$ & $2,3 \times 10^{1}$ & $4,3 \times 10^{1}$ & $<0,3 \times 10^{1}$ \\
\hline & \multicolumn{5}{|c|}{ Coliformes termotolerantes (NMP/g) } \\
\hline Refrigerado sem Vácuo & $<0,3 \times 10^{1}$ & $<0,3 \times 10^{1}$ & $<0,3 \times 10^{1}$ & $<0,3 \times 10^{1}$ & $<0,3 \times 10^{1}$ \\
\hline Refrigerado com Vácuo & $<0,3 \times 10^{1}$ & $<0,3 \times 10^{1}$ & $<0,3 \times 10^{1}$ & $<0,3 \times 10^{1}$ & $<0,3 \times 10^{1}$ \\
\hline Congelado sem Vácuo & $<0,3 \times 10^{1}$ & $<0,3 \times 10^{1}$ & $<0,3 \times 10^{1}$ & $<0,3 \times 10^{1}$ & $<0,3 \times 10^{1}$ \\
\hline
\end{tabular}


A contagem de aeróbios psicrotróficos foi baixa em todos os tratamentos até o sétimo dia de armazenamento. Aos 14 dias, o produto mantido sob vácuo refrigerado apresentou contagem de $7,2 \times 10^{4}$. A partir de 21 dias de armazenamento até o final do experimento, os dois tratamentos mantidos sob refrigeração apresentaram contagens elevadas para estes microrganismos. $O$ produto congelado apresentou contagens aceitáveis durante todo o experimento, sendo um produto seguro para o consumidor quanto a aeróbios psicrotróficos.

A contagem de bolores e leveduras (Tabela 9) foi baixa durante todo o período para o produto mantido no tratamento congelado. $O$ apenas refrigerado sem vácuo apresentou contagens aceitáveis (Brasil, 2001) durante todo o período, com exceção dos valores obtidos aos 28 dias de armazenamento. No produto mantido sob vácuo refrigerado, as contagens foram altas aos 14 e 21 dias, com redução aos 28 dias de armazenamento.

De maneira geral, o produto congelado apresentou baixa contagem de coliformes totais durante todo o período, demostrando que o congelamento é eficiente na manutenção da qualidade microbiológica das raízes de mandioca minimamente processadas (Tabela 9). O produto mantido sob vácuo apresentou baixas contagens de coliformes, com exceção dos valores obtidos aos 21 dias de armazenamento. Já o produto mantido apenas sob refrigeração apresentou contagens elevadas no sétimo, $21^{\circ}$ e $28^{\circ}$ dias de armazenamento. A contagem de coliformes termotolerantes atendeu às exigências da Resolução RDC no 12, de 2 de janeiro de 2001 (Brasil, 2001), com valor máximo de <0,3 x 101.

Segundo Nutrição e Saúde (2015), a proliferação de microrganismos durante a armazenagem é evidente em pHs superiores a 4,5. O pH das raízes de mandioca é superior a este valor, correspondendo ao comportamento apresentado na contagem dos microrganismos avaliados nos tratamentos sob refrigeração. Nas raízes minimamente processadas, mantidas sob congelamento, a baixa temperatura foi eficiente no controle do desenvolvimento dos microrganismos indesejáveis no produto, garantindo assim maior vida útil ao mesmo.

\section{Conclusões}

Considerando as análises microbiológicas realizadas, raízes de mandioca das diferentes cultivares estudadas, minimamente processadas, mantidas congeladas podem ser comercializadas durante 28 dias em boas condições de consumo. Sob refrigeração com e sem vácuo, a vida útil das diferentes cultivares minimamente processados é de, no máximo, sete dias.

Raízes de mandioca das cultivares BRS 400, BRS 399 e IAC 576-70 produzidas no Distrito Federal não apresentam variação significativa na coloração das raízes mantidas sob refrigeração, com e sem vácuo, e também no produto congelado durante 28 dias de armazenamento.

Raízes de mandioca minimamente processadas das cultivares BRS 400, BRS 399 e IAC 576-70 produzidas no Distrito Federal apresentam maior vida útil quando submetidas e mantidas sob congelamento, sendo uma alternativa para o aumento da vida útil de raízes de mandioca minimamente processadas.

\section{Agradecimentos}

Os autores agradecem à Empresa Brasileira de Pesquisa Agropecuária (Embrapa), à Fundação Banco do Brasil (FBB) e ao Conselho Nacional de Desenvolvimento Científico e Tecnológico (CNPq), pelo apoio financeiro.

\section{Referências}

Agrianual (2013) Anuário da agricultura brasileira. AgraFNP. 482p.

Aguiar EB, Valle TL, Lorenzi JO, Kanthack RAD, Miranda Filho H, Granja NP (2011) Efeito da densidade populacional e época de colheita na produção de raízes de mandioca de mesa. Bragantia 70(3):561-569.

Albuquerque JAA, Evangelista MO, Mates APK, Alves JMA, Oliveira NT, Sediyama T, Silva AA (2014) Occurrence of weeds in Cassava savanna plantations in Roraima. Planta Daninha 32(1):91-98.

Arruda MC, Jacomino AP, Trevisan MJ, Jeronimo EM, Moretti CL (2011) Atmosfera modificada em laranja 'Pêra' minimamente processada. Bragantia 70(3):664-671.

Barry-Ryan C, O'beirne D (1998) Quality and shelf life of fresh cut carrot slices as affected by slicing method. Journal of Food Science 63(1):851-856.

Bezerra VS, Pereira RGFA, Carvalho VD, Vilela ER (2002) Raízes de mandioca minimamente processada: efeito do branqueamento na qualidade e conservação. Ciência Agrotécnica 26(3):564-567.

BRASIL (2001) RDC oo 12, de 02 de janeiro de 2001. Dispõe Sobre o Regulamento Técnico Sobre os Padrões Microbiológicos Para Alimentos. Brasília.

Butarelo SS, Beleia A, Fonseca ICB, Ito KC (2004) Hidratação de tecidos de raízes de mandioca (Manihot esculenta Crantz.) e gelatinização do amido durante a cocção. Ciência e Tecnologia de Alimentos 24(3):311-315.

Caruso JGB, Camargo R (1984) Microbiologia de alimentos. In: Camargo R (ed) Tecnologia dos produtos agropecuários-alimentos, Nobel. p. 35-49. 
Carvalho CRL, Mantovani DMB, Carvalho PRN, Moraes RM (1990) Análises químicas de alimentos. ITAL. 121p.

Carvalho AV, Seccadio LL, Souza TCL, Ferreira TF, Abreu LF (2011) Avaliação físico-química e sensorial de mandioca pré-processada armazenada sob congelamento. Boletim do CEPPA 29(2):223-228.

Carvalho LJCB, Vieira EA, Fialho JF, Souza CRB (2011) A genomic assisted breeding program for cassava to improve nutritional quality and industrial traits of storage root. Crop Breeding and Applied Biotechnology 11(4):289-296.

Cavalini FC (2004) Índices de maturação, ponto de colheita e padrão respiratório de goiabas 'Kumagai' e 'Paluma'. Esalq (Dissertação de mestrado em Fisiologia e Bioquímica de Plantas).

Ceni GC, Colet R, Peruzzolo M, Witschinski F, Tomicki L, Barriquello AL, Valduga E (2009) Avaliação de componentes nutricionais de cultivares de mandioca (Manihot esculenta Crantz). Alimentos e Nutrição 20(1):107-111.

Chitarra MIF, Chitarra AB (2005) Pós-colheita de frutos e hortaliças: fisiologia e manuseio. UFLA. 785p.

Costa MGS (2005) Parâmetros para elaboração de mandioca pronta para consumo armazenada sob refrigeração. Unicamp (Tese de doutorado em Engenharia Agrícola).

Cruz CD (2001) Programa genes: aplicativo computacional em genética e estatística. UFV. 648p.

El-Sharkawy MA (2012) Stress-tolerant cassava: the role of integrative ecophysiology-breeding research in crop improvement. Open Journal of Soil Science 2(1):162-186.

Halsey ME, Olsen KM, Taylor NJ, Chavarriaga-Aguirre P (2008) Reproductive biology of cassava (Manihot esculenta Crantz) and isolation of experimental field trials. Crop Science 48(1):49-58.

HUNTERLAB (2008) Insight on color: CIE $L^{*} a^{*} b^{*}$ color scale. Reston, VA, USA.

Farias Neto JT, Moura EF, Resende MDV, Celestino Filho P, Augusto SG (2013) Genetic parameters and simultaneous selection for root yield, adaptability and stability of cassava genotypes. Pesquisa Agropecuária Brasileira 48(12):1562-1568.

Feniman CM (2004) Caracterização de raízes de mandioca (Manihot esculenta Crantz) do cultivar IAC 576-70 quanto à cocção composição química e propriedades do amido em duas épocas de colheita. Esalq. (Dissertação de mestrado em Ciência e Tecnologia de Alimentos).
Fialho JF, Vieira EA, Silva MS, Moraes SVP, Fukuda WMG, Filho MOSS, Silva KN (2009) Desempenho de variedades de mandioca de mesa no Distrito Federal. Revista Brasileira de Agrociência 15(1-4):31-35.

Favaro SP (2003) Composição química e estrutura de paredes celulares de variedades de mandioca (Manihot esculenta Crantz) com tempos de cocção diferentes. UEL. (Tese de doutorado em Ciência e Tecnologia de Alimentos).

Fernandes AM, Soratto RP, Evangelista RM, Nardin I (2010) Qualidade físico-química e de fritura de tubérculos de cultivares de batata na safra de inverno. Horticultura Brasileira 28(3):299-304.

Fukuda WMG, Borges MF (1988) Avaliação qualitativa de cultivares de mandioca de mesa. Revista Brasileira de Mandioca 7(1):63-71.

Fukuda WMG, Silva SO, Iglesias C (2002) Cassava breeding. Crop Breeding and Applied Biotechnology 2(4):617-638.

Fukuda WMG, Fukuda C, Vasconcelos O, Folgaça JL, Neves HP, Carneiro GT (2006) Variedades de mandioca recomendadas para o Estado da Bahia. Bahia Agrícola 7(3):27-30.

Lulianelli GCV, Tavares MIB (2011) Caracterização de diferentes amostras de mandioca por espectroscopia de ressonância magnética nuclear. Polímeros 21(2):131-136.

Lorenzi JO (1994) Variação na qualidade culinária das raízes de mandioca. Bragantia 53(2):237-245.

Lorenzi JO, Valle TL, Monteiro DA, Peressin VA, Kanthack RAD (1996) Variedades de mandioca para o estado de São Paulo. IAC. 58p.

Lorenzi JO (2003) Mandioca. CATI. 110p.

Mezzalira I, Costa CJ, Vieira EA, Fialho JF, Silva MS, Denke ML, Silva KN (2013) Pre-germination treatments and storage of cassava seeds and their correlation with emergence of seedlings. Journal of Seed Science 35(1):113-118.

Mezette TF, Carvalho CRL, Morgano MAM, Silva MG, Parra ESB, Galera JMSV, Valle TL (2009) Seleção de clones-elite de mandioca de mesa visando a características agronômicas, tecnológicas e químicas. Bragantia 68(3):601-609.

Mezette TF, Blumer CG, Veasey EA (2013) Morphological and molecular diversity among cassava genotypes. Pesquisa Agropecuária Brasileira 48(5):510-518.

Moreto AL, Neubert EO (2014) Avaliação de produtividade e cozimento de cultivares de mandioca de mesa (aipim) em diferentes épocas de colheita. Revista Agropecuária Catarinense 27(1):59-65. 
Moura EF, Farias Neto JT, Sampaio JE, da Silva DT, Ramalho GF (2013) Identification of duplicates of cassava accessions sampled on the North Region of Brazil using microsatellite markers. Acta Amazonica 43(4):461-468.

NUTRIÇÃO E SAÚDE. Apostila de tecnologia de alimentos princípios. Disponível em: http://www.ebah.com.br/tecnologia-dos-alimentospdf-a46754.html (Acesso em 02 de mar de 2015).

Oliveira MA de, Cereda MP (1999) Efeito da película de mandioca na conservação de goiabas. Brazilian Journal of Food Technology 2(1,2):97-102.

Oliveira MA, Pantaroto S, Cereda MP (2003) Efeito da sanitização e de agente antioxidante em raízes de mandioca minimamente processadas. Brazilian Journal of Food Technology 6(2):339-344.

Oliveira MA (2010) Conservação pós-colheita de mandioca de mesa. Disponível em: <http://www.cerat.unesp.br/compendio/palestras/pal estra7.pdf> (Acesso em 20 ago 2014).

Oliveira MN, Xavier JHV, Silva FAM, Scopel E, Zoby JLF (2009) Efeitos da introdução do sistema de plantio direto de milho por agricultores familiares do município de Unaí, MG (Cerrado Brasileiro). Pesquisa Agropecuária Tropical 39(1):51-60.

Pereira AS, Lorenzi JO, Valle TL (1985) Avaliação do tempo de cozimento e padrão de massa cozida em mandioca de mesa. Revista Brasileira de Mandioca 4(1):27-32.

Pereira LTP, Beléia A del P (2004) Isolamento, fracionamento e caracterização de paredes celulares de raízes de mandioca (Manihot esculenta Crantz). Ciência e Tecnologia de Alimentos 24(1):59-63.

Ramos PAC, Sedihyama T, Viana AES, Pereira DM, Finger FL (2013) Efeito de inibidores da peroxidase sobre a conservação de raízes de mandioca in natura. Brazilian Journal Food Technology 16(2)116-124.

Santos JS, Oliveira MBPP (2012) Revisão: Alimentos frescos minimamente processados embalados em atmosfera modificada. Brazilian Journal Food Technology 15(1)1-14.
Senter SD, Chapman GW, Forbus WR, Payne JA (1991) Sugar and non-volatile acid composition of persimmons during maturation. Journal of Food Science 56(4):989-991.

Shami NJIE, Moreira EAM (2004) Licopeno como agente antioxidante. Revista de Nutrição 17(.2):227236.

Silva VV, Soares NFF, Geraldine RM (2003) Efeito da embalagem e temperatura de estocagem na conservação de mandioca minimamente processada. Revista Brazilian Journal of Food Technology 6(2):197-202.

Silva N, Junqueira VCA, Silveira NFA, Taniwaki MH, Dantos RFS, Gomes RAR (2007) Manual de métodos de análise microbiológica de alimentos. Livraria varela. 552p.

Silva JA da. (2009) Conservação de mandioca (Manihot esculenta Crantz) minimamente processada sob diferentes atmosferas modificadas. Ufpa (Dissertação de mestrado em Ciência e Tecnologia de Alimentos).

Suppakul P, Chalernsook B, Ratisuthawat B, Prapasitthi S, Munchukangwan N (2013) Empirical modeling of moisture sorption characteristics and mechanical and barrier properties of cassava flour film and their relation to plasticizing-antiplasticizing effects. LWT - Food Science and Technology 50(1)290-297.

TACO (2006) Tabela brasileira de composição de alimentos. Disponível em: http://www.unicamp.br/nepa/taco/contar/taco_versao 2.pdf (Acesso em: 06 jun 2014).

Vieira EA, Fialho JF, Silva MS, Paula-Moraes SV, Oliveira CM, Anjos JRN, Rinaldi MM, Fernandes FD, Guimarães Júnior R (2011) BRS Japonesa: new sweet cassava cultivar for the Distrito Federal region. Crop Breeding and Applied Biotechnology 11(2):193-196. 